\title{
Rectifilter for electric arc plasma plant
}

\section{Evseev Alexei Mikhailovich ${ }^{1}$, Meshcheryakov Victor Nikolayevich ${ }^{2}$, Titov Sergey Sergeyevich ${ }^{3}$}

${ }^{1}$ Postgraduate, assistant of professorElectric drive chair, faculty of automation and computer science, Lipetsk State Technical UniversityLipetsk, Russiaevseev_am@stu.lipetsk.ruThe reported study was funded by RFBR, project number 19-38-90154 «Research of active energy filtration systems, adapted to electric arc technological processes»

${ }^{2}$ Doctor of sciences (Engineering), Professor, Head of chairElectric drive chair, faculty of automation and computer science, Lipetsk State Technical UniversityLipetsk, Russiamesherek@stu.lipetsk.ru

${ }^{3}$ Candidate of sciences (Engineering), DirectorLLC "Research and Development enterprise System 48”Lipetsk, Russia

algebra934@yandex.ru

Article History: Received: 11 January 2021; Accepted: 27 February 2021; Published online: 5 April 2021

Abstract: This article presents the results of the development and research of a new type of AC-DC converter - a filterrectifier (or rectifilter). The object of application of the proposed device is an industrial plant of electric arc plasma processing, the operation of which requires maintaining a constant value of the arc current and is accompanied by a high level of harmonic distortion and consumed reactive energy. From the point of view of the reactive power compensation and harmonic filtering strategy, the rectifilter can be attributed to active electric power filters and FACTS, however, from the position of the main function performed, it is a direct current source, an AC to DC converter, an active rectifier. This work describes in detail the principles of operation of the control system and the hardware architecture of the device. Mathematical modeling of the rectifilter and analysis of the graphs of the consumed alternating current, rectified current, analysis of the harmonic composition and power factor in comparison with the thyristor rectifier of an electric arc plasmatron were carried out.

Keywords: electric arc; plasmatron; energy efficiency; FACTS; active power filter; active rectifier; current source

\section{Introduction}

Existing energy-intensive electrotechnological plants in most cases have in their structure a converter that plays the role of a voltage source. For such solutions, methods have been developed that maximize the efficiency of energy consumption $(3,5,28)$. In processes and plants that require maintaining a predetermined current value, such as an electric arc plasma plant, the operation of the converter as a current source is required $(1,2,13,18$, 27). At the same time, the existing energy conversion systems significantly worsen the quality of the supplied electric energy, which leads to an increase in the cost of using technological equipment, a decrease in the stability of the power supply network, and a decrease in the resource of the equipment $(8,26)$.

In the matter of increasing the efficiency of energy consumption using FACTS, the most important tasks are to ensure the best operation speed and accuracy when restoring the required waveform of current or voltage $(23$, 30). This is largely due to the fact that in the process of modernizing technological complexes, electronic and electrical systems are often used that introduce additional harmonic distortions and reactive energy flows into the power supply network (20). Increasing the range and level of harmonic distortion steadily reduces the efficiency of most FACTS $(7,22)$. In addition, being mainly an element of the power supply network on the transmission side, they are not able to reduce the loss of electricity in equipment and the elements on the consumer side. Thus, the most promising solution to improve the energy efficiency of large technological plants is to install FACTS on the consumption side and control energy flows taking into account the process flow, and, as a consequence, the modes of electricity consumption.

There are solutions that allow you to adapt the FACTS hardware architecture for specific technological plants, as well as solutions for joint control of the technological process (16) and the process of restoring the waveform of the consumed current. Considering the class of adapted systems for active energy filtering (AAEF), it should be noted that their adaptation at the level of hardware solutions can only be realized with rectifiers built according to the topology of the voltage source $(10,11,14,15,17,21,24)$. At the same time, for the considered systems of plasma electric arc processing, the topology of the rectifier in the form of a current source is required. Therefore, the first requirement for AAEF in the complex of an electric arc plasmatron will be the ability to restore the current waveform at the point of connection of the current source. In addition, when developing AAEF for an electric arc plasmatron, it is necessary to take into account changes in the technological process. The application of this adaptation approach leads to a significant increase in the overall dimensions of the electrical complex, since, in addition to the existing plasmatron converter, the installation of an AAEF converter will be required. It follows that the most promising from the point of view of technical and economic efficiency will be the adapted electric power filtration systems installed in or instead of the plasmatron converter $(12,19$, 29) which can be defined as the second requirement for the developed system. 
The proposed solution for constructing a harmonic filtering system and reactive power compensation is as follows. Instead of a controlled rectifier on single-operation thyristors of the plasmatron converter, a rectifier should be installed on fully controlled semiconductor switches with a maximum switching frequency exceeding the order of distorting harmonics. Such a rectifier, on the one hand, will play the role of a current source for the formation and maintenance of the electric arc, on the other hand, it will form the effective consumption of electric current. Based on the value of the required electric arc current, as well as the instantaneous values of currents and voltages in phases at the connection point, the rectifier control system will set the waveform of the consumed current. Ensuring operation speed can also be achieved by optimizing the algorithms for generating control pulses of the control system.

\section{Experimental plant}

\subsection{Hardware}

The rectifier of the experimental plant is a single-level three-phase bridge rectifier on IGBTs with blocking diodes. The schematic diagram of the power unit is shown in Fig. 1.

On IGBT gates provide switching signals from the control system. The control system receives:

- measured instantaneous values of phase currents consumed from the main and line voltages at the connection point of the plant (from the measuring unit MB),

- measured current values in a DC circuit (from CS current sensor),

- the measured values of the potential difference between the anode and cathode (from the voltage sensor VS).

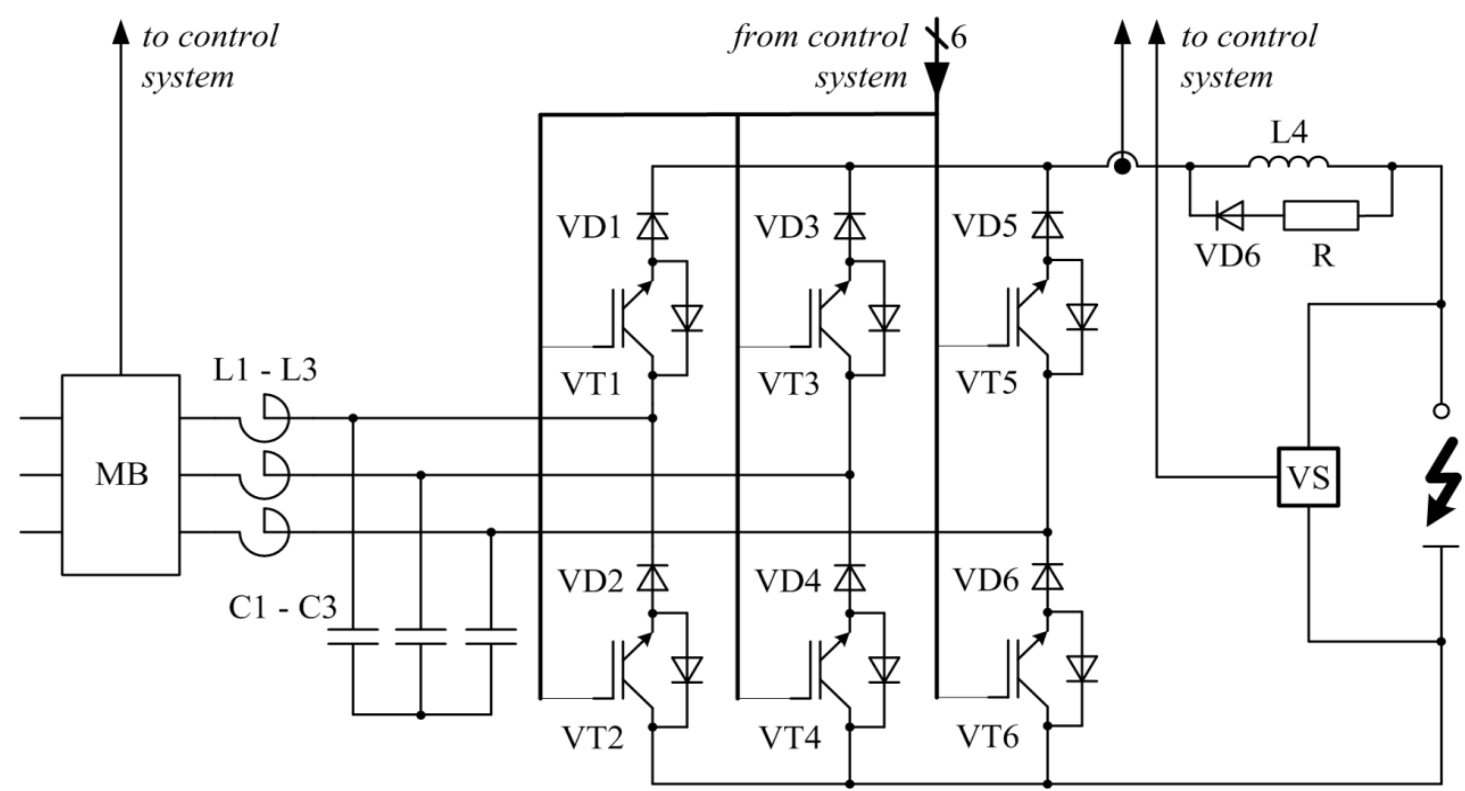

Fig. 1. Schematic diagram of the power part of the experimental plant

The plasmatron rectifier is connected to the main through the reactor blocks L1 - L3 and linearly connected capacitors C1 - C3. They are installed to reduce, respectively, ripple current and voltage. VD1-VD6 diodes are required to block reverse diodes in the IGBTs VT1-VT6. In addition to the CS current sensor, a choke L4 is included in the DC link, which serves to accumulate energy and maintain a constant direct current value. The circuit, consisting of the reverse diode VD7 and resistor R, serves to discharge the inductance, and protects the converter from overvoltage at the time of breaking the DC circuit. The anode of the electric arc plasmatron is connected to the positive contact of the converter, and the cathode - to the negative.

\subsection{Control System}

The essence of the proposed control method is to determine the waveforms of the consumed phase currents, which, on the one hand, will provide the required value of the arc current in the DC link of the converter, and on the other hand, will correspond in harmonic composition and phase shifts to the waveforms of the corresponding phase voltages. The functional diagram of the rectifilter control system is shown in Fig. 2.

The operation of the control system is as follows.

Based on considerations of simplifying the logic of the formation of control pulses, we will limit the number of combinations $\mathrm{N}=6$ so that three of them and their corresponding inverse combinations commute exclusively two phases at the input of the converter. Thus, the state $\mathrm{Q}$ of the converter switches will be determined by the following system of equations: 


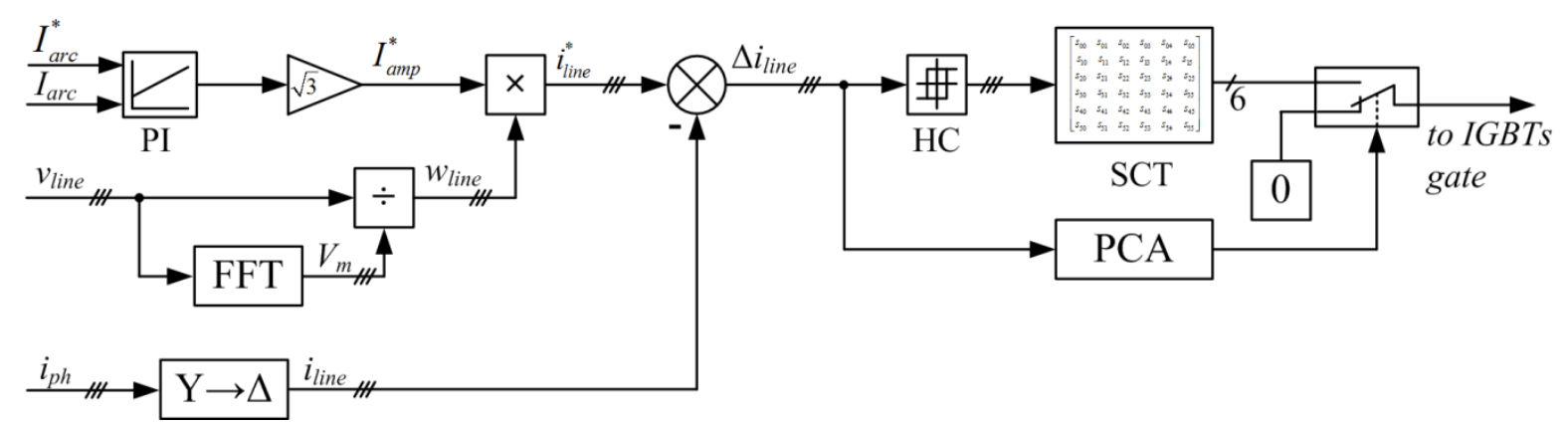

Fig. 2. Functional diagram of the control system of the experimental plant

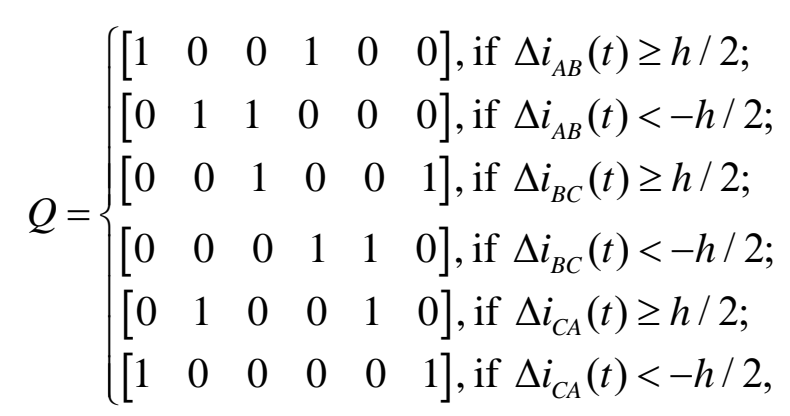

where $\Delta i_{A B}(t), \Delta i_{B C}(t), \Delta i_{C A}(t)$ is the differences between calculated and reference hypothetical linear currents, [A]. System of these currents $\Delta i_{\text {line }}(t)=\left\{\Delta i_{A B}(t) ; \Delta i_{B C}(t) ; \Delta i_{C A}(t)\right\}$;

$h$ - the width of the hysteresis zone of the hysteresis controller HC, [A]. It is usually set at $5 \div 10 \%$ of the nominal consumed phase current.

This system of equations is presented in the control system in the form of a switching combinations table SCT and hysteresis controllers HC.

The difference is determined, as explained above, by the following equation

$$
\Delta i_{\text {line }}(t)=i_{\text {line }}^{*}(t)-i_{\text {line }}(t) \text {, }
$$

where $i_{\text {line }}^{*}(t)=\left\{i_{A B}^{*}(t) ; i_{B C}^{*}(t) ; i_{C A}^{*}(t)\right\}$ is the system of reference hypothetical linear currents, [A];

$i_{\text {line }}(t)=\left\{i_{A B}(t) ; i_{B C}(t) ; i_{C A}(t)\right\}$ - system of calculated hypothetical linear currents, [A].

Calculation of hypothetical linear currents $i_{\text {line }}(t)$ is carried out by phase-linear transformations of the measured phase currents $i_{\text {phase }}(t)=\left\{i_{A}(t) ; i_{B}(t) ; i_{C}(t)\right\}$ :

$$
\left\{\begin{array}{l}
i_{A B}(t)=i_{A}(t)-i_{B}(t) ; \\
i_{B C}(t)=i_{B}(t)-i_{C}(t) ; \\
i_{C A}(t)=i_{C}(t)-i_{A}(t) .
\end{array}\right.
$$

Setting of hypothetical linear currents has the following form:

$$
\left\{\begin{array}{l}
i_{A B}^{*}(t)=I_{a m p}^{*} \cdot w_{A B}(t) ; \\
i_{B C}^{*}(t)=I_{a m p}^{*} \cdot w_{B C}(t) ; \\
i_{C A}^{*}(t)=I_{a m p}^{*} \cdot w_{C A}(t),
\end{array}\right.
$$

where $w_{A B}(t), w_{B C}(t), w_{C A}(t)$ - reference waveforms of currents of unit amplitude, dimensionless quantity. System of these signals $w_{\text {line }}(t)=\left\{w_{A B}(t) ; w_{B C}(t) ; w_{C A}(t)\right\}$;

$I_{a m p}^{*}$ - the scaled amplitude of the reference hypothetical linear currents, [A]. This value is obtained by the following ratio:

$$
I_{\text {amp }}^{*}=\sqrt{3} \cdot I_{P I}^{*},
$$


where $I_{P I}^{*}$ is the output signal of the PI controller, [A].

The PI controller input receives the values of the reference arc current $I_{\text {arc }}^{*}$, [A] and the actual value of the arc current, $I_{\text {arc }}[\mathrm{A}]$.

$$
w_{\text {line }}(t)=\frac{v_{\text {line }}(t)}{V_{\text {mline }}},
$$

where $v_{\text {line }}(t)=\left\{v_{A B}(t) ; v_{B C}(t) ; v_{C A}(t)\right\}$ is the system of measured linear voltages, [V].

$V_{m \text { line }}=\left\{V_{m A B} ; V_{m B C} ; V_{m C A}\right\}$ - the system of amplitudes of the measured linear voltages, [V], which is determined using the tools of the fast Fourier transform (FFT) by the ratio:

$$
V_{\text {mline }}=\frac{2 \sqrt{2}}{T} \sqrt{(A)^{2}+(B)^{2}} \text {. }
$$

where $A=\int_{t-T}^{t} v_{\text {line }}(t) \cos (2 \pi f t) d t, B=\int_{t-T}^{t} v_{\text {line }}(t) \sin (2 \pi f t) d t$,

$T$ - period of fundamental harmonic, [c],

$f=T^{-1}$ - fundamental harmonic frequency, $[\mathrm{Hz}]$.

One of the important elements of the proposed control system is also a prioritizer, the operation of which is determined by the priority calculation algorithm (PCA) and consists in controlling the signal transmission on each of the IGBT control lines depending on the level of harmonic distortion and the magnitude of the phase shift of phase currents. This algorithm allows to solve the problem of the appearance of additional distortions in the waveform of the consumed current during regulation.

\section{Modelling Results}

The operation of the proposed system was simulated in MATLAB Simulink. Fig. 3a shows graphs of the phase voltage $u_{a}$ and the consumed phase current $i_{a}$ during the operation of the rectifilter without a prioritizer. As can be seen from the phase current graph, such a rectifilter operation leads to additional distortions in the current waveform. These distortions appear in cases when the control system simultaneously tries to fulfill several conditions for compensation of linear currents. The result of the prioritizer operation reflects the current graph in Fig. 3b. As can be seen, the waveform of the phase current $i_{a}$ repeats the waveform of the phase voltage $u_{a}$ without distortion.
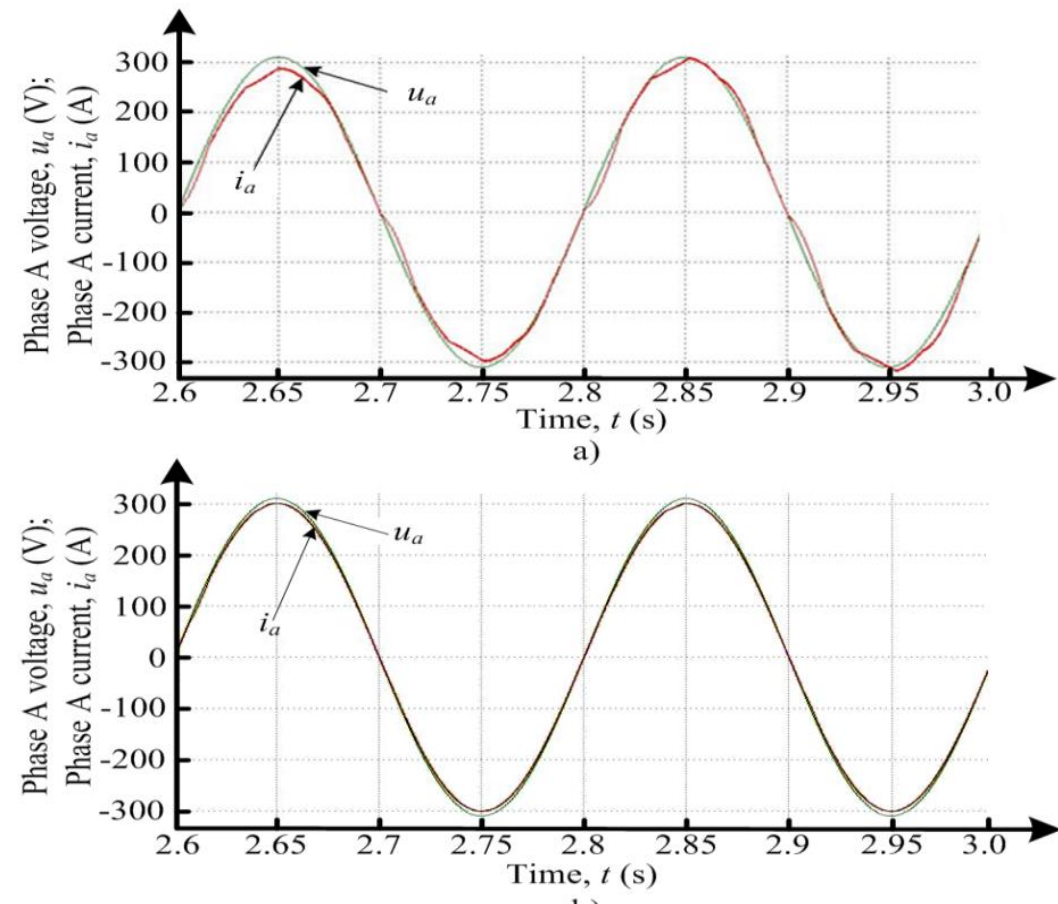

b)

Fig. 3. Graphs of phase A current and phase A voltage: 
a - without prioritizer, $\mathrm{b}$ - with prioritizer

With the hysteresis width $h=0.05 \cdot I_{\text {arc }}$, the total level of harmonic distortion of the phase currents after the saturation process of the DC inductor is: $T H D_{I} \leq 1.13 \%$. The level of harmonic distortion of the current when using a thyristor AC/DC converter of the electric arc plasmatron is $T H D_{I}=8.3 \div 38.5 \%$. The power factor of the rectifilter is $P F=1$; thyristor converter is $P F=0.43 \div 0.86$. The function of maintaining a given level of arc current is confirmed by the graphs in Fig. 4. From the graphs of the current it can be seen that the actual value of the arc current corresponds to the reference value.

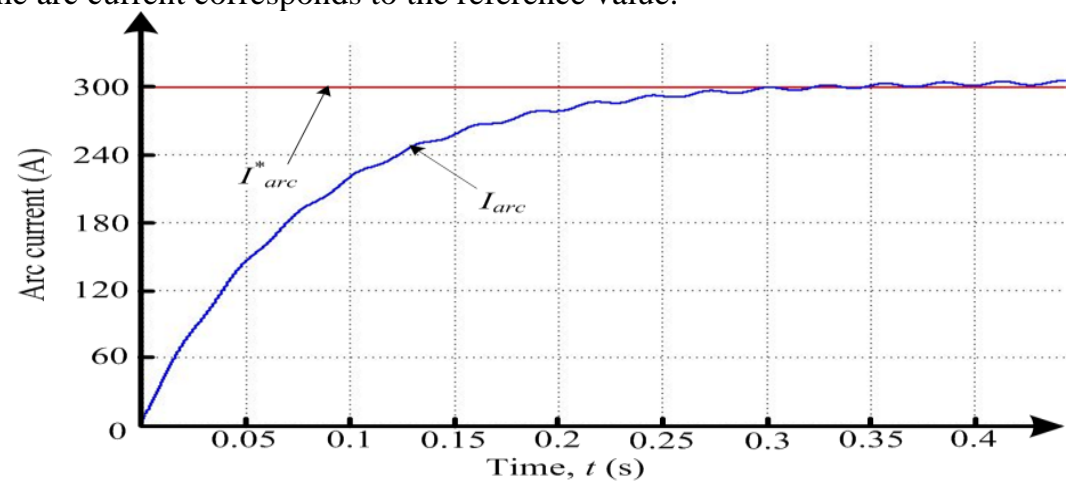

Fig. 4. Graphs of giving and actual arc currents

\section{Conclusions}

Making a conclusions about the originality of the proposed solution, one should pay attention to a similar class of devices - active rectifiers AFE (9), which have a voltage inverter topology and are not suitable for systems powered by a current source. There are solutions that allow the use of this type of rectifiers as current sources $(6,25)$, however, the use of direct current at the output of the rectifier as a target parameter of the control algorithm leads to a high level (relative to active power filtering systems) of harmonic distortions of the consumed current and does not allow control reactive energy flows. In view of the use of instantaneous values of phase currents at the input of the converter as a target parameter of the control algorithm in the proposed solution, such a converter should be compared with flexible ac-transmission systems. When comparing the control systems of the filter-rectifier and active power filters, it should be noted that in the latest solutions using the topology of the current source (4), the PQ method is used as an algorithm for determining the reference values of the recovered phase current, based on calculating the power averaged over the period and filtration, and characterized by lower performance in comparison with the proposed method. Also, in such a solution (4), PWM modulation is taken as the main method for generating control pulses, which in this topology differs in significant voltage ripples on the AC side, rather than when using hysteresis regulators used to control rectifier filters.

\section{References}

1. Anshakov A.S., Cherednichenko V.S., Urbakh E.K. et al. The treatment of mixed wastes using the thermal plasma / Progress in Plasma Processing of Materials/ Ed.P.Fauchais, J.Amouroux. N. Y.: Begell House, Inc., 1999. P. 737-743. [Book]

2. Astanei, D., Burlica, R., Dirlau, I. D., \& Andrusca, M. (2018). Ayrton Relation Applied for Medium Voltage AC Electrical Discharges. 2018 International Conference and Exposition on Electrical And Power Engineering (EPE), 18-19 Oct. 2018, Iasi, Romania. doi:10.1109/icepe.2018.8559816. [Conference Proceedings]

3. Chen, M., Chakraborty, S., \& Perreault, D. J. (2018). Multitrack power factor correction architecture. 2018 IEEE Applied Power Electronics Conference and Exposition (APEC), 4-8 March, San Antonio, TX, USA. doi:10.1109/apec.2018.8341094. [Conference Proceedings]

4. Exposito, B.; Carneiro, H.; Pinto, G.; Couto, C.; Afonso, J.L., Simulations of a current-source Shunt Active Power Filter with Carrier-Based PWM and Periodic Sampling Modulation Techniques, Proceedings of the 2011-14th European Conference on Power Electronics and Applications (EPE 2011), pp.1-8, 30 Aug. - 1 Sept., 2011. [Conference Proceedings]

5. Fang, F., Tian, H., \& Li, Y. (2020). SVM Strategy for Mitigating Low Order Harmonics in Isolated AC-DC Matrix Converter. IEEE Transactions on Power Electronics, 36 (1), 583 - 596. doi:10.1109/tpel.2020.3000497. [Journal] 
6. Goh, M., Choi, S., Yu, J. \& Kim, I. High Power Factor Induction Heating Power Supply for Forging Applications Using Three-Phase Three-Switch PWM Current Source Rectifier. 2019 22nd International Conference on Electrical Machines and Systems (ICEMS), Harbin, China, 11-14 Aug. 2019, pp. 1-5, doi: 10.1109/ICEMS.2019.8922408. [Conference Proceedings]

7. Gokozan H., Taskin S., Seker S., Ekiz H. A neural network based approach to estimate of power system harmonics for an induction furnace under the different load conditions, Electrical Engineering, Vol. 97, no. 2, 2015. DOI: 10.1007/s00202-014-0320-3. [Journal]

8. Jaiswal, G., Ballal, M., Tutakne, D., \& Suryawanshi, H. (2019). Impact of Power Quality on the Performance of Distribution Transformer. IEEE Industry Applications Magazine, XX1-XX1. doi:10.1109/mias.2018.2875207. [Journal]

9. Kumar, A. \& Srungavarapu, G. Algorithm-based direct power control of active front-end rectifiers. IET Power Electronics, 12 (4), pp. 712-718, doi: 10.1049/iet-pel.2018.5256. [Journal]

10. Liu, H., Li, C., Zheng, Z., Liu, J., \& Li, Y. (2019). Shunt Isolated Active Power Filter With Common DC Link Integrating Braking Energy Recovery in Urban Rail Transit. IEEE Access, 7, 3918039191. doi:10.1109/access.2019.2906329. [Journal]

11. Liu, H., Zheng, Z., Li, C., Liu, J., \& Li, Y. (2019). Shunt Isolated Active Power Filter with Common DC Link in Urban Rail Transit System. IEEE Vehicle Power and Propulsion Conference (VPPC), 1417 Oct. 2019, Hanoi, Vietnam. doi: 10.1109/VPPC46532.2019.8952174. [Conference Proceedings]

12. Mangkalajan, S., Ekkaravarodome, C., Jirasereeamornkul, K., Thounthong, P., Higuchi, K., \& Kazimierczuk, M. K. (2018). A Single-Stage LED Driver Based on ZCDS Class-E Current-Driven Rectifier as a PFC for Street-Lighting Applications. IEEE Transactions on Power Electronics, 33(10), 8710-8727. doi:10.1109/tpel.2017.2780088. [Journal]

13. Mazzoni, L.; Janajreh, I. Plasma gasification of municipal solid waste with variable content of plastic solid waste for enhanced energy recovery // 2016 International Renewable and Sustainable Energy Conference (IRSEC) - Marrakech, Morocco, 14-17 Nov. 2016 - DOI: 10.1109/IRSEC.2016.7984049. [Conference Proceedings]

14. Meshcheryakov V.N., Evseev A.M. Device for compensation of harmonic distortion of currents in systems with a tyristor voltage converter. Elektrotekhnicheskie sistemy i kompleksy [Electrotechnical Systems and Complexes], 2017, No. 3(36), pp. 4-10. (In Russian). DOI: 10.18503/2311-8318-2017-3(36)-4-10. [Journal]

15. Meshcheryakov V.N., Evseev A.M., Boikov A.I. Active energy filter for compensation of harmonic distortion in motor soft starter, 17th International Ural Conference on AC Electric Drives (ACED), Ekaterinburg, Russia, 26-30 March 2018, pp. 1-6. DOI: 10.1109/ACED.2018.8341701. [Conference Proceedings]

16. Meshcheryakov V.N., Evseev A.M., Didenko E.E. Joint control of looper electric drive of finishing mill group and active energy filter, International Russian Automation Conference (RusAutoCon), Sochi, Russia, 09-16 Sept. 2018, pp. 1-6. DOI: 10.1109/RUSAUTOCON.2018.8501757. [Conference Proceedings]

17. Meshcheryakov V.N., Habibullin M.M., Pikalov V.V., Valtchev S. Active Power Filter with Common DC Link for Compensation of Harmonic Distortion in Power Grids, 16th International Power Electronics and Motion Control Conference and Exposition (PEMC 2014). Antalya, 2014, pp. 1586-1590. [Conference Proceedings]

18. Meshcheryakov, V.N., Pikalov, V.V., Evseev, A.M., Danilova, O. V., Ambrosimov, S. K.. (2019) Electric Arc Plasma Installation with Control Information-Measuring System. 2019 1st International Conference on Control Systems, Mathematical Modelling, Automation and Energy Efficiency (SUMMA), 20-22 Nov. 2019, Lipetsk, Russia. doi: 10.1109/SUMMA48161.2019.8947588. [Conference Proceedings]

19. Miao, Z., Tong, H., Jin, X., Yao, W., Lu, Z. \& Ma, Z.. DQ-Frame Zero-Crossing Effect Modeling and Current Distortion Compensation Method for Vienna Rectifier, IEEE Transactions on Power Electronics, 35 (7), pp. 7612-7623, doi: 10.1109/TPEL.2019.2957540. [Journal]

20. Nikolaev, A. A., Tulupov, P. G., \& Tulupova, O. V. (2019). Melting stage diagnostic in different types of electric arc furnaces based on the analysis of the harmonic composition of the electric arc current. 2019 8th International Conference on Modeling Simulation and Applied Optimization (ICMSAO), 15 17 April 2019, Manama, Bahrain, doi:10.1109/icmsao.2019.8880402. [Conference Proceedings]

21. Parvez, M., Mekhilef, S., Tan, N. M. L., \& Akagi, H. (2015). An improved active-front-end rectifier using model predictive control. 2015 IEEE Applied Power Electronics Conference and Exposition (APEC). doi:10.1109/apec.2015.7104341. [Conference Proceedings]

22. Priyashree S., Pooja A.B., Mahesh E., Vidya H.A. Harmonic suppression in a non-linear load using three phase shunt active power filter, 2016 Biennial International Conference on Power and 
Energy Systems: Towards Sustainable Energy (PESTSE), Bangalore, 2016, pp. 1-6. [Conference Proceedings]

23. Raheni T.D., Thirumoorthi P. Intelligent control of shunt active power filter for minimization of current harmonics, IEEE Region 10 Conference (TENCON 2017), Penang, 2017, pp. 2846-2851. DOI: 10.1109/TENCON.2017.8228346. [Conference Proceedings]

24. Rodrigues, P. L. S., Jacobina, C. B., Costa, A. E. L. \& Cavalcanti de Oliveira, Í. A.. (2019) Universal Active Power Filter Based on Three Three-Leg Converters and a Single DC-link. 2019 IEEE Energy Conversion Congress and Exposition (ECCE), Baltimore, MD, USA, 2019, pp. 2902-2909, doi: 10.1109/ECCE.2019.8912903. [Conference Proceedings]

25. Roseline, J. A. \& Senthil Kumaran, M. Generalized Modulation Technique for Current Source Converters. TENCON 2018 - 2018 IEEE Region 10 Conference, Jeju, Korea (South), 2018, pp. 03830388, doi: 10.1109/TENCON.2018.8650255. [Conference Proceedings]

26. Savina, N. V., Myasoedov, Y. V., \& Myasoedova, L. A. (2018). Influence of Quality of the Electric Energy on Reliability of Electrical Supply Systems. 2018 International Multi-Conference on Industrial Engineering and Modern Technologies (FarEastCon). doi:10.1109/fareastcon.2018.8602690. [Conference Proceedings]

27. Sturm, G. S. J., Mucoz, A.N., Aravind, P.V., Stefanidis, G.D. Microwave-Driven Plasma Gasification for Biomass Waste Treatment at Miniature Scale / IEEE Transactions on Plasma Science - 2016, Vol.: 44 , Issue: 4, pp. 670-678. [Journal]

28. Valipour, H., Mahdavi, M., Ordonez, M., Ksiazek, P., \& Khandekar, R. (2020). Extended Range Bridgeless PFC Converter with High Voltage DC Bus and Small Inductor. IEEE Transactions on Power Electronics, 36 (1), 157 - 173. doi:10.1109/tpel.2020.2997667. [Journal]

29. Xue, C., Ding, L., Li, Y., \& Zargari, N. R. (2019). Improved Model Predictive Control for High-Power Current-Source Rectifiers Under Normal and Distorted Grid Conditions. IEEE Transactions on Power Electronics, 35 (5), 4588 - 4601. doi:10.1109/tpel.2019.2946251. [Journal]

30. Yakimov, I. A., \& Gasiyarov, V. R. (2018). The Improvement of Operational Efficiency of High Power Electric Arc Furnace Due to Electrical Equipment. 2018 International Conference on Industrial Engineering, Applications and Manufacturing (ICIEAM), 15-18 May 2018, Moscow, Russia, doi:10.1109/icieam.2018.8728560. [Conference Proceedings] 